\title{
GENERATING ELECTRICITY FROM PAVEMENT
}

\author{
Prathima G $^{1}$, Sachin Jaiswal ${ }^{2}$, Unica Khadka ${ }^{3}$, Vishal Thakker ${ }^{4}$ \\ ${ }^{I}$ Department of Civil Engineering, Nitte Meenakshi Institute of Technology, Baglur cross, Yelahanka, Bengaluru, \\ 560064 \\ ${ }^{2}$ Department of Civil Engineering, Nitte Meenakshi Institute of Technology, Baglur cross, Yelahanka, Bengaluru, \\ 560064 \\ ${ }^{3}$ Department of Civil Engineering, Nitte Meenakshi Institute of Technology, Baglur cross, Yelahanka, Bengaluru, \\ 560064 \\ ${ }^{4}$ Department of Civil Engineering, Nitte Meenakshi Institute of Technology, Baglur cross, Yelahanka, Bengaluru, \\ 560064
}

\begin{abstract}
In today's world, due to vast expansion of infrastructure and the increase in population has caused our natural resources to deplete considerably, causing an energy crisis. Thus it is important to use renewable sources of energy, for example, solar radiation from the sun. Various methods of energy harvesting systems are being developed and studied. Energy harvesting from pavement is one of its kind which involves encapsulating the heat from the pavement surface and converting it to electrical energy. The pavement surface absorbs the solar radiation and gets heated, thus increasing the internal temperature of the pavement. The heat is tapped and converted into electrical energy using Thermo Electric Generators (TEGs). TEG is a thermoelectric component which works on the principle of Seebeck Effect that generates EMF when there is a temperature difference between its two faces. This potential difference tends to allow the electrons to flow from higher to lower potential thus generating electricity. A similar project work had been carried out earlier at International Conference On Recent Advances in Engineering Sciences (ICRAES-2014) with ISSN 2349-9575 Volume 2 Issue 1 January-June 2014 (Journal Of Civil Engineering Technology and Research organized by MS Ramaiah Institute Of Technology). Earlier project was conducted by preparing samples in the laboratory with a use of single TEG to harvest electricity and a voltage of $1.5 \mathrm{~V}$ was generated which was sufficient to light a low voltage LED. The present work was extended for a series of connection of TEGs (3 in no.) in order to obtain more voltage output and the study has produced the outcome of an average voltage of $3.5 \mathrm{~V}$ throughout the day that may be stored in the batteries and later use it for various applications.
\end{abstract}

Keywords: Renewable, Proportioning, Aggregates, Pavement, Thermoelectric Generators, Voltage, Temperature Difference.

\section{INTRODUCTION}

Energy is available in many different forms such as wind, solar, thermal, mechanical energy, etc. The energy consumption has increased over a period of time due to increased population. The depletion of natural resources has a direct impact on the environment. Energy harvesting is the process of capturing the unused energy from naturally occurring energy sources, accumulating and storing it for later use.

Asphalt pavement is one component for extracting energy. The pavements receive large amount of energy which gets dissipated into the bottom surface. This source can be used to generate electricity from the pavement.

\section{LITERATURE SURVEY}

2.1 The paper by Prathima G, et. $\mathrm{Al}^{[1]}$ used a single based on the principle of Seebeck Effect. Pavement moulds were casted as per the specifications in the laboratory. Various combinations for heating and cooling were tried, such as, cooling using earthen pot, heat sink and the combination of copper plate and heat sink. The combination of copper plate and heat sink gave the maximum voltage of $1.64 \mathrm{~V}$.

2.2 Guangxi Wu and Xiong (Bill) Yu, IEEE ${ }^{[2]}$ describes the development of energy harvesting system that produces electricity from the thermal gradient across pavement structure. The energy due to temperature difference between the pavement surface and the subgrade soil is collected by this system. This energy system can be used as a localised strategy desirable to power the monitoring sensors in distributed infrastructure such as pavement.

2.3 In the paper by A.Ongel et.al ${ }^{[3]}$ the study for variation of temperature with respect to time and depth was carried out. The temperature is seen to vary at the surface of the pavement. This maximum variation of temperature can lead to the placement of the design system.

2.4 Bao-Liang Chen ${ }^{[4]}$ presents the concept of using a piping network below the surface of asphalt pavements to flow an appropriate fluid, to reduce the temperature of the asphalt pavement reduce Urban Heat Island Effect, and use the heated fluid for different end applications such as 
heating, power generation or refrigeration. The reduced temperature will extend the life of the pavement, while the reduced temperature of the near surface air will lead to savings in energy consumption of adjacent buildings and improvement in air quality (such as by reducing ozone concentration).

\section{MATERIALS AND METHODOLOGY}

\subsection{Materials Required}

Bitumen: The paving bitumen of penetration grade complying with Indian Standard Specifications IS:73 was used.

Table 1 Properties of binder used

\begin{tabular}{|l|l|l|l|}
\hline $\begin{array}{l}\text { Sl. } \\
\text { No. }\end{array}$ & Laboratory Test & Unit & VG-30 \\
\hline 1 & Penetration & $\mathrm{Mm}$ & 45.6 \\
\hline 2 & Softening Point & ${ }^{0} \mathrm{C}$ & 58 \\
\hline 3 & Ductility & $\mathrm{Cm}$ & 81.4 \\
\hline 4 & Specific Gravity & - & 0.97 \\
\hline 5 & Viscosity & Poise & $135^{0}-1.65 \mathrm{p}$ \\
& & & $150^{0}-0.95 \mathrm{p}$ \\
\hline 6 & Flash & ${ }^{0} \mathrm{C}$ & 257 \\
\hline 7 & Fire & ${ }^{0} \mathrm{C}$ & 279 \\
\hline
\end{tabular}

Coarse Aggregates: The coarse aggregates consisted of crushed rock or gravel retained on the $4.75 \mathrm{~mm}$ sieve. The materials are clean, hard and durable of cubical shape free from dust or any other organic and deleterious materials.

Fine Aggregates: Fine aggregates consisted of crushed material passing $4.75 \mathrm{~mm}$ sieve and retained on 75 micron sieve. The materials are clean, hard and durable of cubical shape free from dust or any other organic and deleterious materials.

Table 2 Properties of Aggregates Used

\begin{tabular}{|c|c|c|c|}
\hline $\begin{array}{l}\text { Sl. } \\
\text { No }\end{array}$ & Properties tested & $\begin{array}{l}\text { Test } \\
\text { Results }\end{array}$ & $\begin{array}{l}\text { MORTH } \\
\text { Specification } \\
\mathrm{s}\end{array}$ \\
\hline 1 & Aggregate Impact Test & $27 \%$ & $30 \% \max$ \\
\hline 2 & $\begin{array}{l}\text { Los Angeles Abrasion } \\
\text { Test }\end{array}$ & $16.3 \%$ & $30 \% \max$ \\
\hline 3 & $\begin{array}{ll}\text { Aggregate } & \text { Crushing } \\
\text { Value Test } & \end{array}$ & $25 \%$ & $45 \% \max$ \\
\hline 4 & $\begin{array}{l}\text { Combined Elongation } \\
\text { and Flakiness index }\end{array}$ & $21.4 \%$ & $30 \% \max$ \\
\hline 5 & Water Absorption Test & $1.2 \%$ & $2 \% \max$ \\
\hline 6 & $\begin{array}{l}\text { Specific Gravity Test } \\
\text { for Coarse Aggregates }\end{array}$ & 2.70 & $2.5-3.0 \max$ \\
\hline 7 & $\begin{array}{l}\text { Specific Gravity Test } \\
\text { for Fine Aggregates }\end{array}$ & 2.77 & - \\
\hline 8 & $\begin{array}{l}\text { Specific Gravity } \text { Test } \\
\text { for Stone Dust }\end{array}$ & 2.68 & - \\
\hline
\end{tabular}

\subsection{Proportioning of Materials}

The aggregates are proportioned and blended obtain a uniform mix complying with the standards in Table-3.

Table 3 Composition of Bituminous Macadam

\begin{tabular}{|l|l|l|}
\hline $\begin{array}{l}\text { Mix designation } \\
\text { Nominal aggregate } \\
\text { size }\end{array}$ & $\begin{array}{l}\text { Grading 1 } \\
\text { Layer thickness } \\
80-100 \mathrm{~mm}\end{array}$ & $\begin{array}{l}\text { Grading 2 } \\
\text { 50-75 mm }\end{array}$ \\
\hline $\begin{array}{l}\text { IS sieve (mm) } \\
\text { Cumulative \% by weight of total } \\
\text { aggregate passing }\end{array}$ \\
\hline 45 & 100 & - \\
\hline 37.5 & $90-100$ & - \\
\hline 26.5 & $75-100$ & 100 \\
\hline 19 & - & $90-100$ \\
\hline 13.2 & $35-61$ & $56-88$ \\
\hline 4.75 & $13-22$ & $16-36$ \\
\hline 2.36 & $4-19$ & $4-19$ \\
\hline 0.3 & $2-10$ & $2-10$ \\
\hline 0.075 & $0-8$ & $0-8$ \\
\hline $\begin{array}{l}\text { Bitumen content \% } \\
\text { by } \\
\text { Weight of total } \\
\text { mixture }\end{array}$ & $3.1-3.4$ & $3.3-3.5$ \\
\hline Bitumen grade & 35 to 90 & 35 to 90 \\
\hline
\end{tabular}

Note: Appropriate bitumen contents for conditions in cooler areas of India may be up to $0.5 \%$ higher subject to the approval of the Engineer.

\subsection{Rothfuch's Method of Proportioning}

Proportioning of materials by Rothfuch's method was adopted for this procedure. This method may be used when a number of materials have to be mixed together for obtaining a desired gradation or design gradation. The desired gradation may be decided either based on recommended grain size distribution charts. On the graph sheet with $\mathrm{Y}$-axis representing percentage passing and $\mathrm{X}$-axis is representing particle size. A diagonal line is drawn from the point corresponding to $100 \%$ passing, maximum particle size of the material, to a point corresponding to $0 \%$ passing, smallest particle size of the material. The different particle sizes are marked on $\mathrm{X}$-axis corresponding to the mean values of percentage finer taken on the $\mathrm{Y}$-axis, making use of the table of desired gradation or a suitable gradation equation. Thus we get the gradation of the aggregates to be used in the sample preparation shown in Table-4 


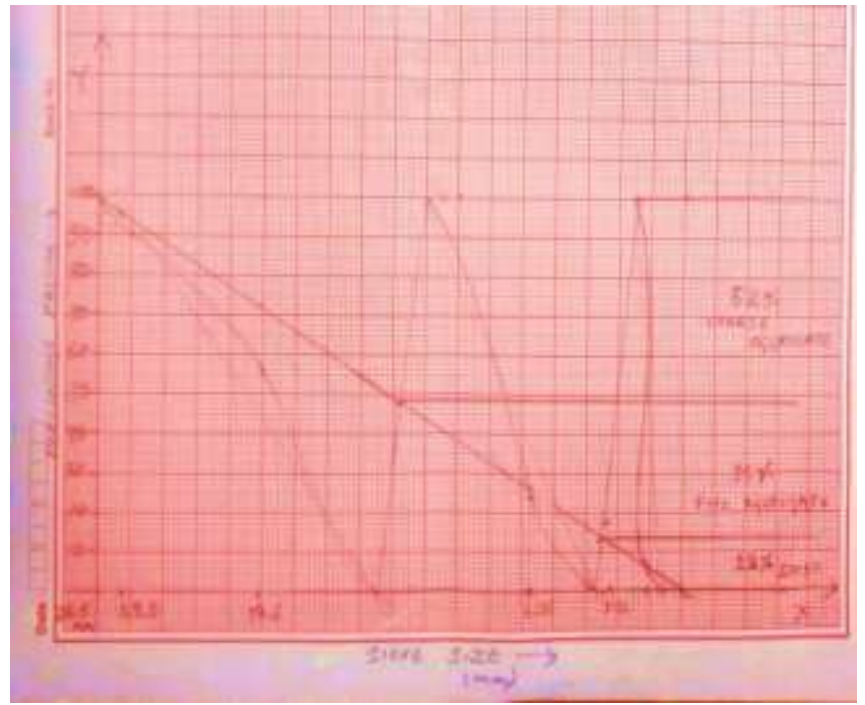

Fig 1 Percentage Passing vs Particle Size

Table 4 Gradation Chart

\begin{tabular}{|l|l|l|l|l|}
\hline $\begin{array}{l}\text { Siev } \\
\text { e } \\
\begin{array}{l}\text { Size } \\
(\mathrm{Mm} \\
)\end{array}\end{array}$ & $\begin{array}{l}\text { Weight } \\
\text { Retaine } \\
\text { dKg })\end{array}$ & $\begin{array}{l}\text { Percentag } \\
\text { e Retained } \\
(\%)\end{array}$ & $\begin{array}{l}\text { Cumulative } \\
\text { Percentage } \\
\text { Retained } \\
(\%)\end{array}$ & $\begin{array}{l}\text { Percentag } \\
\text { e Passing } \\
(\%)\end{array}$ \\
\hline 26.5 & 0 & 0 & 0 & 100 \\
\hline 19 & 0.870 & 9.67 & 9.67 & 90.33 \\
\hline 13.2 & 2.930 & 32.55 & 42.22 & 57.78 \\
\hline 9.5 & 1.180 & 13.11 & 55.33 & 44.67 \\
\hline 4.75 & 1.610 & 17.89 & 73.22 & 26.78 \\
\hline 4 & 0.090 & 1.00 & 74.22 & 25.78 \\
\hline 3.55 & 0.080 & 0.89 & 75.11 & 24.89 \\
\hline 2.36 & 0.690 & 7.67 & 82.78 & 17.22 \\
\hline 1.7 & 0.345 & 3.83 & 86.61 & 13.39 \\
\hline 1.18 & 0.010 & 0.11 & 86.72 & 13.28 \\
\hline 0.6 & 0.070 & 0.78 & 87.5 & 12.5 \\
\hline 0.3 & 0.350 & 3.89 & 91.39 & 8.61 \\
\hline 0.75 & 0.650 & 7.11 & 98.5 & 1.5 \\
\hline & & & & \\
\hline
\end{tabular}

\subsection{Procedure as per Standard Specifications}

The proportion of aggregates in accordance with the specified weight is taken.

- Coarse aggregate $-52 \%$,

- Fine aggregate- $35 \%$

- Dust- $13 \%$

- The bitumen of $3.5 \%$ of the total weight of the sample is taken.

The aggregates are heated to a temperature as per standards. The aggregates are then mixed with the binder which is heated to a pouring consistency.

The mixture is then taken to the site and was laid in layers and compacted as per the standard specifications.
Components Used in Voltage Studies

1. Arduino Board

2. GSM Module

3. Thermo Electric Generators (TEGs)

4. Connecting Wires and Jumpers

5. Adaptors

6. Heat Sink

The above materials are required to continuously record the voltage produced throughout the day. The readings were obtained via SMS using the GSM Module.

\subsection{Methodology}

The TEGs were connected to the Arduino Board to record the voltage produced using a program. A separate program was used to transfer these readings via SMS using GSM Module. Due to the temperature difference between the two surfaces of the TEGs, i.e. the hot and cold surfaces, voltage is produced.

Different trials were undertaken for the study:

\section{Placing copper plate directly on the existing pavement and laying a layer of pavement above it.}

A copper plate of surface area 1 sq.ft. was used in the first trial. The plate was placed on an existing pavement and another layer of pavement surface was laid over it of thickness $40 \mathrm{~mm}$, covering $3 / 4^{\text {th }}$ of the copper plate. The top surface of the existing pavement acts as a bottom layer. The TEGs were placed in the remaining portion of the copper plate above which heat sinks were placed to cool the top surface. The remaining $1 / 4^{\text {th }}$ portion and the TEG setup was covered using a wooden box for insulation as well as safety purpose as shown in the figure below.

In this setup, the voltage obtained was not satisfactory .It was noticed that, the part of the copper plate inside the box was not getting heated, thus electricity couldn't be generated.

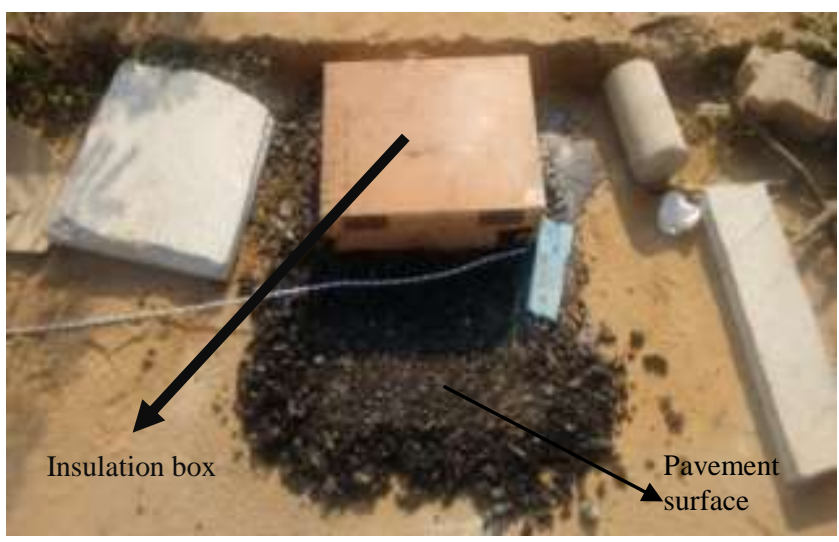

Fig 2 Setup After Laying Pavement 


\section{Excavating a part of pavement surface and placing} a single TEG on the copper plate and another TEG on the pavement surface

A part of pavement was excavated and a TEG was placed directly on the copper plate and a heat sink was placed over it. Another TEG was placed over the pavement surface directly.

The result obtained from the trial was not satisfactory as there was no temperature difference obtained between the two surfaces of the TEG. The heat sink was not effective as it was directly exposed to the sun.

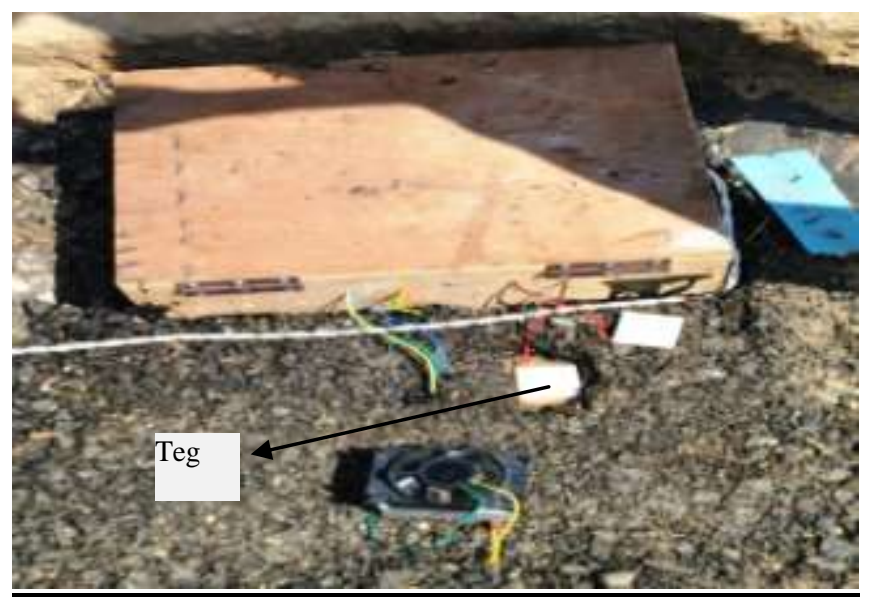

Fig 3 Excavating a part of Pavement and placing a TEG on it and placing another TEG on the Surface

\section{Exposing of the copper plate to the direct sun}

The $3 / 4^{\text {th }}$ portion of the copper plate were exposed to the sun's radiations. The result observed was no heat transfer was undertaken from the exposed surface of the copper plate to the insulated plate.

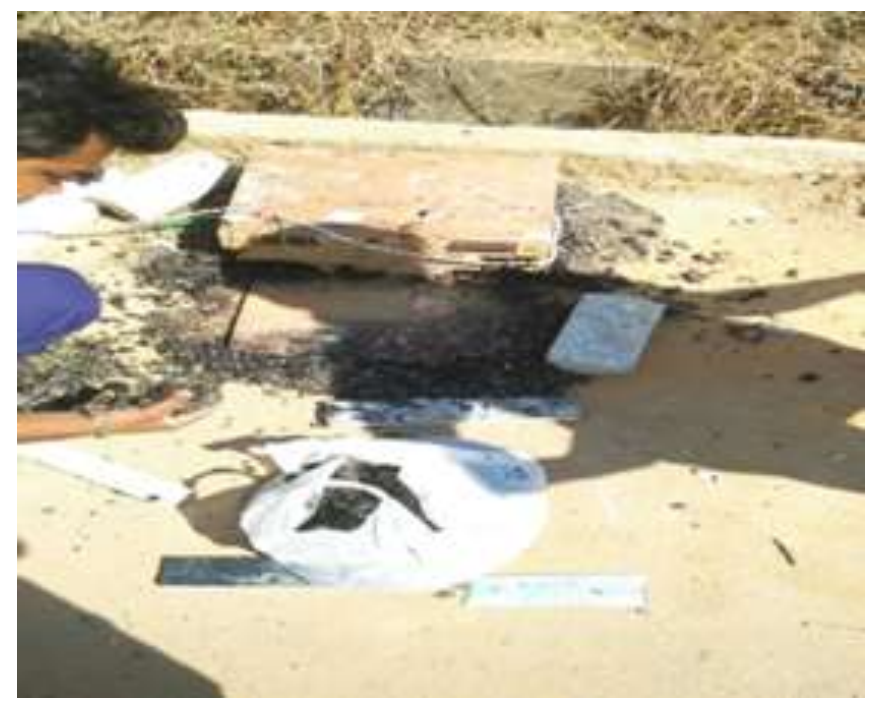

Fig 4 Exposing the copper plate directly to Sun

\section{Copper board embedded in between the pavement} layer

As observed from the above trial, the copper plate wasn't transferring heat and required insulation. It was therefore replaced with a copper board. A layer of pavement was laid on the existing pavement over which the copper board was placed. One more layer of pavement was then casted over the copper board covering $3 / 4^{\text {th }}$ portion as done in trial 1 .

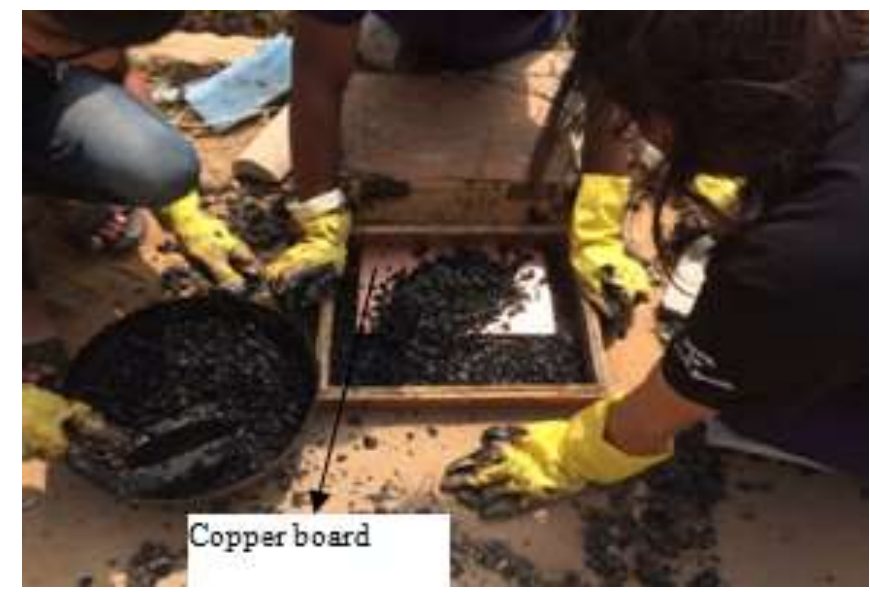

Fig 5 Embedding the Copper Board in Pavement

\section{RESULTS AND DISCUSSION}

Amongst all the trials that were conducted, the first three trials could not give satisfactory output. After replacing the copper plate with an insulated copper board and embedding the board in the pavement surface a maximum voltage upto $5 \mathrm{~V}$ was obtained.

The Arduino board used could take maximum input of 5 volts and 3 TEGs were able to give voltage upto $5 \mathrm{~V}$. Therefore, only 3 TEGs were connected in series. The voltage readings were obtained for every 15 minutes interval. As the voltage fluctuates in every second it is not possible to get a constant output. The voltage obtained varied from 0 to $5 \mathrm{~V}$ depending upon the climatic conditions at every instant.

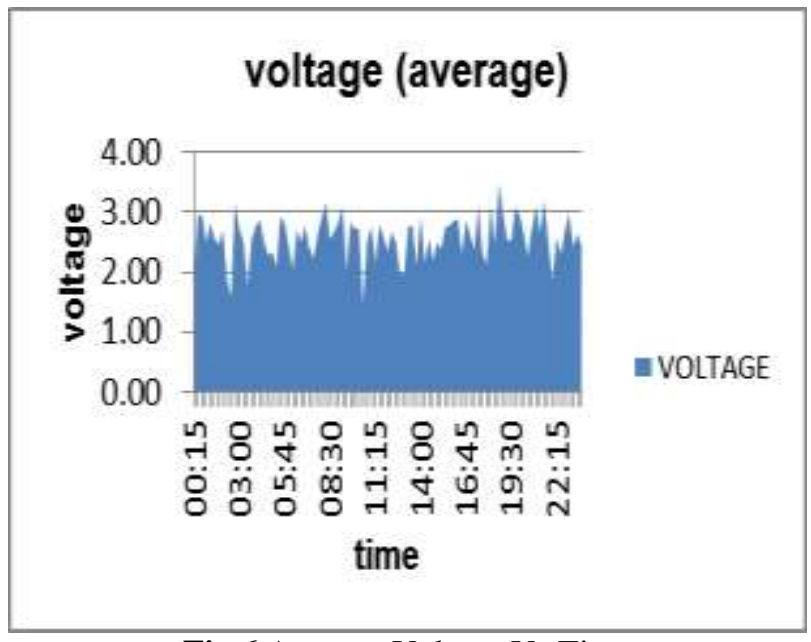

Fig 6 Average Voltage Vs Time 
From this result, it is concluded that the use of multiple TEGs in series could generate more voltage than generated by using a single TEG.

\section{CONCLUSION}

From the earlier project it was observed that the combination of copper plate for the hotter side and heat sink for the colder side was the most effective setup. When using a pure copper plate in the first 3 trials it was observed that the heat got dissipated downwards as the plate was not insulated. Due to this, the remaining $1 / 4^{\text {th }}$ portion of the copper plate was not getting heated.

In order to overcome this problem, the copper plate was replaced with a copper board which was insulated by wood. The maximum voltage obtained by connecting 3 TEGs in series was $5 \mathrm{~V}$. The voltage obtained varied from 0 to $5 \mathrm{~V}$ depending upon the climatic conditions at every instant.

The exposed portion of the copper board and the electrical equipment's were insulated by a wooden box. Due to this, the heat entrapped in the copper board did not dissipate and temperature difference was maintained even during the night time.
Therefore, by connecting TEGs in series an appreciable amount of voltage was drawn due to the temperature difference between two surfaces of the TEG.

\section{FUTURE SCOPE}

\section{Storage}

As per the results obtained we have noticed that we can generate varying voltage throughout the day. This voltage generated can be accumulated and stored in a capacitor circuit of suitable.

The circuit shown in figure 19 is to store the current coming from the TEGs connected in a series of three as a DC supply which the capacitor will filter and supply constant $5 \mathrm{~V}$ input to the battery for storing the current and ultimately will be able to light up the multiple no LEDs connected in parallel to the battery via an automated switch.

The automatic switch consists of an LDR (Light Dependant Resistor) which at low intensity of light will supply the power to the LEDs via micro controller unit (Arduino).

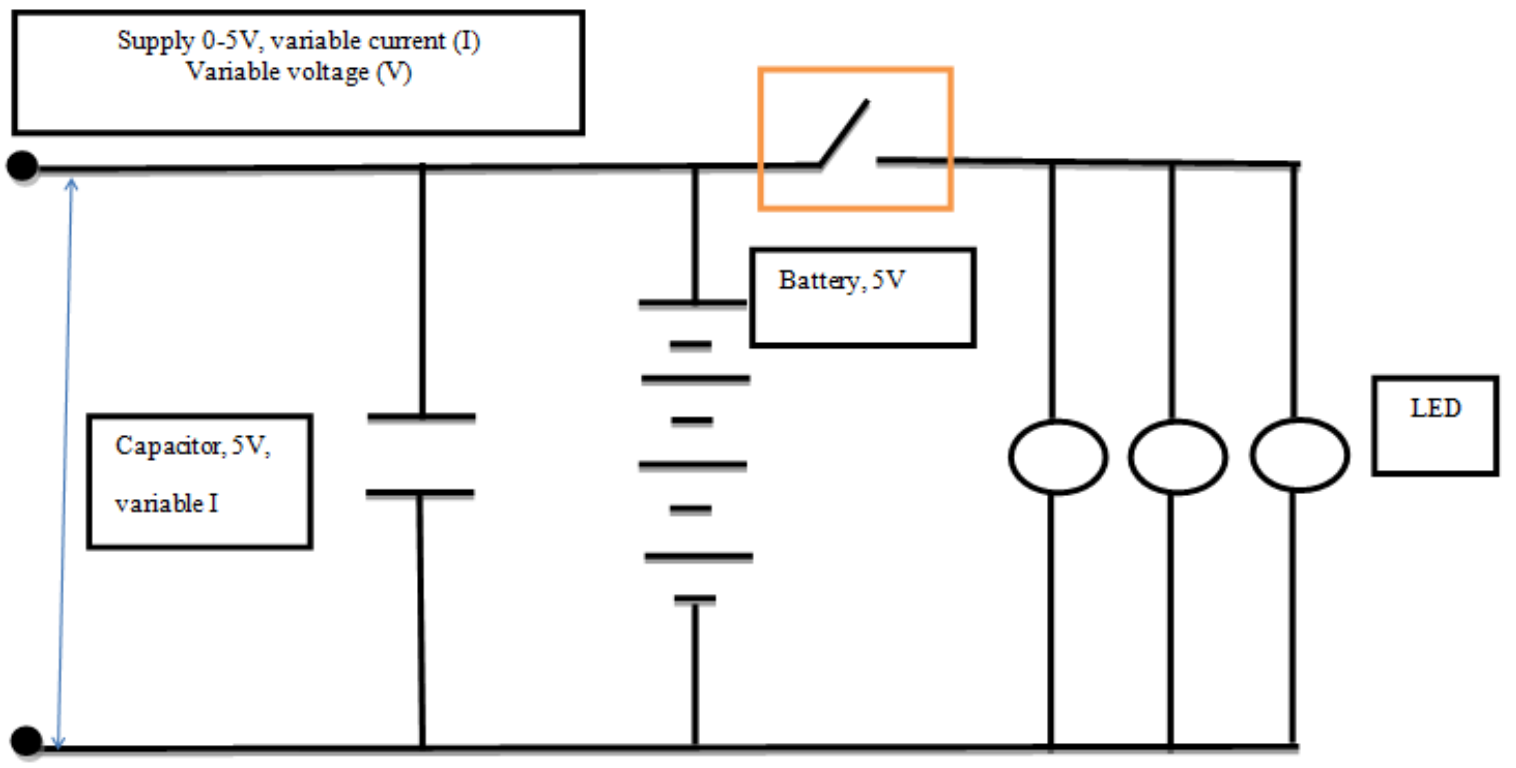

Fig 7 Simple Battery Charging Circuit

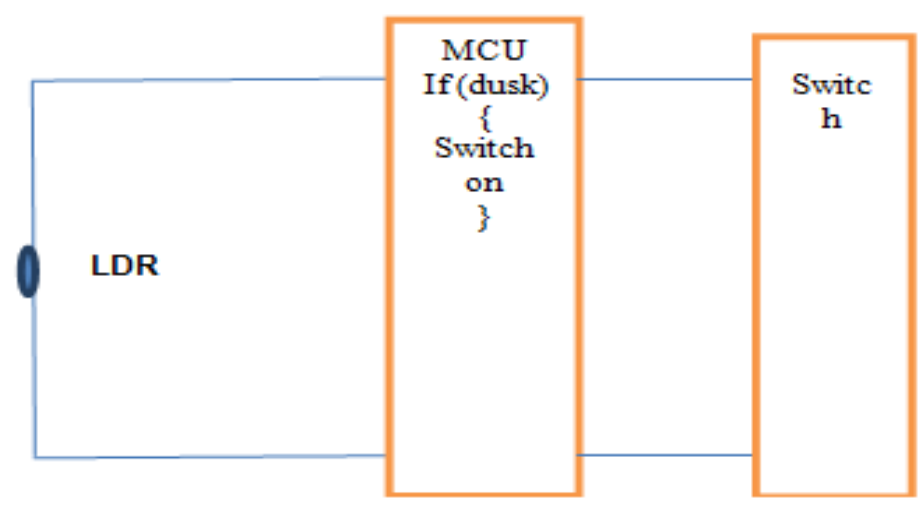

Fig 8 Control of Switch in the Main Circuit 


\section{ACKNOWLEDGMENT}

We would like to thank our HOD, Dr. Bharthi Ganesh, Department of Civil Engineering, NMIT, Bangalore and Dr. H C Nagaraj, (Principal, NMIT, Bangalore) for giving us the opportunity to undertake this project and for the necessary guidance which helped us to complete the project work successfully.

We would like to convey our special thanks to our project guide Mrs. Prathima G, (Assistant professor, Department of Civil Engineering, NMIT, Bengaluru) for helping us throughout the project and guiding us in each stage of our project.

We extend our heart full thanks to our seniors Mr. Adithya Rao P, Mr. Aditya Kothari, Mr. Jagadish Raj S and Mr. Yeshvanth $\mathrm{K}$, for handing over their project to us and helping us out in every stage of the project.

We would also like to express our deep sense of gratitude to our junior Mr. Santosh Kumar P, Department of Electronics and Communication Engineering, for helping us in our project with the design of electrical circuits and the programming required.

A special thanks to our Institution and other faculty members, without which this project would have been a distant reality.

\section{REFERENCES}

[1] Harvesting Energy from Pavement Surface by Mrs Prathima G, Aditya R, Aditya K, Jagdish R, Yeshvanth K. (ISSN 2349-9575 VOL 2).

[2] System Design to Harvest Thermal Energy Across Pavement Structure by Guangxi Wu and Xiong (Bill) $\mathrm{Yu}$, IEEE [1].

[3] Analysis of 30 Years of Pavement Temperatures using the Enhanced Integrated Climate Model (EICM) by A. Ongel, J. Harvey (CALIFORNIA DEPARTMENT OF TRANSPORTATION).

[4] Harvesting energy from asphalt pavements and reducing the heat island effect - white paper-1 by Bao-Liang Chen, Sankha Bhowmick and Rajib B. Mallick (November 2008).

[5] Text book of Highway Engineering by S.K. Khanna and C.E.G. Justo.

[6] Base and Surface Courses (Bituminous), Section 500, Ministry of Road Transport and Highway (MORTH) specifications. 